\title{
La escritura dinámica de Mario Bellatin: del texto al teatro y del teatro al texto*
}

Fecha de recepción: 10 de marzo de 2018

Fecha de aprobación: 15 de mayo de 2018

\section{Resumen}

Hacia finales del siglo XX y comienzos del XXI se producen en diferentes regiones de Latinoamérica textos narrativos que responden a una búsqueda por establecer vínculos con prácticas artísticas (tanto dentro del texto como fuera de él) en las que el cuerpo adquiere un lugar fundamental. El presente artículo se propone analizar $L a$ escuela del dolor humano de Sechuán (2005) y Poeta ciego (2010) de Mario Bellatin a partir de la figura de la puesta en escena, entendida, desde su desplazamiento a la escritura, como la disposición de un espacio-escenario en el que los personajes ejecutan determinadas acciones (culturales, rituales, teatrales) mediante una voz enunciativa particular. Finalmente, a partir de esta figura los textos ponen en escena tanto cuerpos performáticos como un "tercer cuerpo" (en el sentido de Esposito) que se ubica fuera del enunciado.

Palabras claves: literatura; puesta en escena; cuerpos performáticos; Tercer cuerpo; Bellatin.

Citar: Ríos, M. C. (enero-junio de 2018). La escritura dinámica de Mario Bellatin: del texto al teatro y del teatro al texto. La Palabra,(32), 99-116. doi. org/10.19053/01218530.n32.2018.8167.

\section{Marina Cecilia Ríos}

Profesora de la Universidad de Buenos Aires, Facultad de Filosofía y Letras, Instituto de Literatura Hispanoamericana. Doctorando.

riosmarina@hotmail.com

*Artículo de reflexión producto de la investigación doctoral: Figuraciones del arte en narrativas contemporáneas de César Aira, Diamela Eltit, Mario Bellatin y Gabriela Cabezón Cámara e Iñaki Echeverría de la Universidad de Buenos Aires, Facultad de Filosofía y Letras. El doctorado es financiado por el Consejo Nacional de Investigaciones Científicas y Técnicas (CONICET). 


\section{la palabra}

\section{The Dynamic Writing of Mario Bellatin: from Text to Theater and Theater to Text}

\section{Abstract}

Towards the end of XXth century and the beginning of the XXIst in Latin America, narrative texts are produced which respond to the search for a relationship between literature and art (both inside texts and outside them). In this relationship, the body has a fundamental role.

This paper aims at analyzing Mario Bellatin's La escuela del dolor humano de Sechuán [The Szechuan School of Human Suffering] (2005) and Poeta ciego [Blind Poet] (2010) by considering the figure of mise-en-scène. In its displacement into literary writing, this figure is understood as the arrangement of the stage-like space where characters perform cultural, ritual and theatrical actions through a particular narrative voice. Finally, the mise-en-scène stages performatic bodies as well as a "third body", using Esposito's term, which remains outside enunciation.

Keywords: Literature; Mise-en-scène; Performatic bodies; Third body; Bellatin.

\section{L'écriture dynamique de Mario Bellatin: du texte au théâtre et du théâtre au texte}

\section{Résumé}

Vers la fin du XXe et le début du XXIème siècle des textes narratifs dans différentes régions de l'amérique-latine visent à établir des liens avec des pratiques artistiques (tant à l'intérieur qu'à l'extérieur du texte) dans lesquels le corps acquiert une place fondamentale. Nous analyserons La escuela del dolor humano de Sechuán (2005) [L'école de la douleur humaine de Sechuán] et Poeta ciego (2010) [Le poète aveugle] de Mario Bellatin, à partir de la figure de la Mise en scène déplacée à l'écriture, comme la disposition d'un espace-scène dans lequel les personnages effectuent certaines actions (culturelles, rituelles, théâtrales) avec une énonciation particulière. Finallement, à partir de cette figure, les textes mettent en scène des corps performatiques comme un «troisième corps» (au sens d'Esposito) placé en dehors de l'énoncé.

Mots - clés: littérature; mise en scène; corps perfomartiques; troisième corps; Bellatin. 
Hacia finales del siglo XX y comienzos del XXI se producen en diferentes regiones de Latinoamérica textos narrativos, con características disímiles entre sí, pero que responden a una búsqueda por establecer vínculos con prácticas artísticas en las que el cuerpo adquiere un lugar fundamental. De modo tal que, se originan novelas, ficciones breves, novelas con dibujos, con fotografías, narraciones que parecen guiones teatrales y ficciones que no respiran por su incansable proliferación de texto tramadas a partir de motivos artísticos. Sin embargo, que una novela redunde sobre motivos ligados a diferentes artes o incorpore sus elementos (teatro, dibujo, cine o fotografía) es una práctica acorde a textos experimentales realizados a lo largo de todo el siglo $\mathrm{XX}^{1}$. En el contexto contemporáneo ${ }^{2}$, no obstante, la relación entre literatura y arte cobra una centralidad destacada que invita detenerse en producciones con estas características para revisar estos vínculos entre literatura, arte y cuerpo.
Para indagar sobre esta cuestión este artículo se centrará en el caso del escritor Mario Bellatin y dos novelas específicas: Poeta Ciego (2010) y La escuela del dolor humano de Sechuán (2005). Las preguntas que dan comienzo a esta indagación son: si la práctica escritural del escritor mexicano incluye la generación y producción de vínculos estrechos con prácticas artísticas tales como el teatro y/o la performance ¿Qué dimensión adquiere esta impronta en las ficciones? Si los cuerpos son parte constitutiva de las artes escénicas ¿Cómo se transponen en los textos literarios? Mario Bellatin en una publicación sobre la Escuela Dinámica de escritores esgrime:

Es aquí donde creo que este proyecto se sitúa en las fronteras, donde de algún modo se desdibuja aquellos que conocemos como literatura y se forma un cuerpo en el cual el ejercicio de la escritura toma la categoría de práctica artística. Y como es obvio, la frontera se configura con dos espacios que permiten pensar que la práctica literaria es capaz de transformar asimismo en literatura el ámbito de las demás artes (Bellatin, 2006, p. 9).

A esta altura ya forma parte del mito biográfico del artista (para usar una expresión aireana) que en la Escuela Dinámica de Escritores que dirigió Bellatin (2000-2010) hay una única prohibición: escribir. Una serie de maestros imparten enseñanzas a todos los aspirantes (o discípulos como prefiere llamarlos el propio Bellatin) sobre experiencias diversas ligadas a la creación pero en la que, los discípulos, no deben llevar sus textos para cotejar. Además hay otra creencia aún más importante explicitada en el epígrafe que es la de pensar en las maneras en que otras artes estructuran sus propias narraciones. El propio escritor refrenda estas conceptualizaciones (en numerosas entrevistas):

Quiero dejar claro que se trata de una misma disciplina. No quiero que se piense que soy cineasta y que también

Algunos ejemplos de ello podrían ser El lugar sin límites (1965) de José Donoso, Farabeuf o la crónica de un instante (1965) de Salvador Elizondo entre otros. La elección de estos dos escritores no es del todo arbitraria. En la narrativa de Donoso se privilegia la preeminencia de cuerpos anormales, travestidos, mutantes y hasta artistas como podemos ver en el personaje de la Manuela en El lugar sin límites o también en el personaje de "el mudito" o la figura del imbunche en El obsceno pájaro de la noche (1970). De modo semejante, Salvador Elizondo escribe Farabeuf a partir de una narrativa que indaga sobre los cuerpos, las mutilaciones e intervenciones pero también sobre el universo del azar: la tabla Ouija, el / Ching (libro de las mutaciones cuyo eco resuenan en novelas de Mario Bellatin) por un lado, y el discurso médico (con textos extra literarios) -que hoy serían susceptibles de leerse desde la perspectiva de la biopolítica- y la fotografía, por otro. Y en los que también se puede reconocer cierta influencia en las experimentaciones de Mario Bellatin.

2 Me refiero a la caracterización que realiza Hartog sobre el contexto en que se producen las narrativas en cuestión entendido éste como desfase de un tiempo "sin tiempo" (en el sentido de la dificultad en la percepción de una progresión cronológica). Esto significa una distancia mayor entre el horizonte de espera y la expectativa hasta casi la ruptura y en la que el pasado, el presente y el futuro se anudan en una coyuntura que parece permanente o en suspensión. De allí, que denomine con el nombre de <presentismo> al contexto actual que también caracteriza como "presente perpetuo, huidizo y casi inmóvil" (Hartog, 2007, p. 40). 
soy fotógrafo. Yo soy escritor. Lo que pasa es que uno sigue escribiendo de distintas maneras. No sólo con el lápiz y el papel. [...] No obstante, hay momentos que con el lápiz y el papel no encuentras respuestas a las preguntas que te haces, y entonces recurro a una cámara fotográfica, una cámara de cine, hago un montaje, una película [...] Yo no veo distinción entre las disciplinas del arte. Para mí es lo mismo ver una película, una obra de teatro. ${ }^{3}$

Subyace, así, la idea de pensar procedimientos comunes para todas las artes aunque sus modos de hacer sean distintos.En el caso de La escuela del dolor humano fue escrita con la intención de llevarla a la puesta en escena aunque no es estrictamente un texto dramatúrgico. En la entrevista que realiza Larrain (2006), Bellatin cuenta este proceso:

- [...] Me pasó otra experiencia semejante con $L a$ Escuela del dolor humano de Sechuán, que incluso fue creada para ser representada. Me encontré con una pareja de directores de [...] Desde el principio coincidimos en algo, yo no tenía una obra de teatro preparada, y ellos no querían una obra hecha $\mathrm{y}$ tradicional. De esta manera, fueron como la excusa para que comenzara a escribir un texto. Lo cual era perfecto para mí, porque era hacer el texto para algo. Entonces nos reuníamos, era la primera vez que implicaba dejar el estudio, iba con los textos y se los leía, y me daban su opinión. Este intercambio era importante, no para hacerles caso o no, sino para sentir el eco de otro que va reaccionando ante el texto en el momento en que está siendo creado. Después [...] convocaron a un taller de teatro integral para trabajarlo. Yo iba a las sesiones en que los participantes aprendían los textos, los iba cotejando en los actores e iba corrigiendo. El trabajo de corrección que uno realiza cotejando con uno mismo, ahora lo hacía con personas de carne y hueso. [...] Fue un proceso que me sirvió para ir afinando la estructura. Hubo muchos cambios estructurales porque veía lo que estaba pasando ahí con los actores (Larrain, 2006: 6).

Por su parte, Poeta Ciego es una novela que mientras estaba en proceso, mientras era un $<$ negativo> como lo llamó Bellatin $^{4}$, se adaptó para una obra de teatro que se tituló Black Out (los cadáveres valen menos que el estiércol). La dirigió un director italiano, Gustavo Frige- rio, junto a Karin Elmore y Mario Bellatin para la escenografía y la adaptación. Al respecto el escritor le cuenta en entrevista a Larrain (2006):

(...) es como si los personajes, las situaciones, que están planteados en los relatos cobraran vida, en tercera dimensión. De esta manera puedo cotejarlos en su absurdidad o lógica interna y consigo seguir trabajando con ellos, hasta que adquieren forma de libro (...) (4).

La versión publicada de Poeta Ciego, entonces, se corrigió a partir de la puesta del cuerpo de los actores. Cito en extenso -más que para darle credibilidad o aval al propio Bellatin- para destacar la puesta del cuerpo de los actores que se realizó en las etapas pre- y/o pos- producción de los libros publicados.

Esta cuestión presenta un problema, podría decirse, en torno al objeto tal como está planteado en este artículo ¿Es posible escindir los textos publicados del resto de los procesos? De ser así ¿Cómo asir estos procesos (obras teatrales, versiones previas de la obra para ser representada, versiones de la obra para ser publicada)? Ya sea que se aborde desde el punto de vis-

\footnotetext{
3 Garduño, O. (2013). Entrevista a Mario Bellatin. Revista Replicante. Recuperado el 15 de diciembre de 2017 de http://revistareplicante.com/entrevista-con-mario-bellatin/

4 "Entonces la primera experiencia teatral fue con este director italiano que trabajo con los archivos, o como yo les llamo negativos, y después se publicó el libro". Cf. Larrain, R. (2006). Entrevista a Mario Bellatin. Revista Orbis Tertius, 11 (12).
} 
ta de la crítica genética ${ }^{5}$ o de la relación entre prácticas artísticas, o bien, desde la literatura, siempre habrá algo que se escapa del proceso de producción.

A partir de esto, el presente artículo focaliza en el «qué se puede leer» acerca de la relación que las ficciones de La escuela del dolor humano y Poeta ciego sugieren entre literatura $\mathrm{y}$ arte escénica (podemos decir a caballo entre teatro y performance) y en donde la figura de la «Puesta en escena» gravita sobre ellas.

El término puesta en escena ${ }^{6}$ es una noción que proviene del teatro, sin embargo, dada la concepción que Bellatin desarrolla sobre la literatura y el arte, se convierte en una categoría que resulta productiva para pensar en cómo los cuerpos se plasman, en sus textos literarios, a partir de una noción que justamente quiere mostrar y hacer visibles a estos cuerpos. En el diccionario de Pavis (1998), la puesta en escena es definida a partir de sus funciones:

Veinstein propone dos definiciones de la puesta en escena, según el punto de vista del gran público y el de los es- pecialistas: 'En una acepción amplia, el término puesta en escena designa el conjunto de los medios de interpretación escénica: decorados, iluminación, música y actuación' (...) 'En una acepción restringida, el término puesta en escena, designa la actividad que consiste en la disposición, en cierto tiempo y en cierto espacio de actuación, de los diferentes elementos de interpretación escénica de una obra dramática'(citado en Pavis, 1998: 362).

Pavis recoge por un lado, la puesta en escena como una noción elemental en la que, en un escenario, se disponen elementos teatrales para la realización del hecho teatral y por otro, en la $<$ interpretación $>$ que requiere una obra dramática para su concreción. Ambas definiciones designan a la puesta en escena como una categoría general en la que se tiene en cuenta, por un lado, la disposición de elementos, espacios y personajes y por otro, los medios técnicos (luces, decorado, actores, etcétera) que hacen posible esta realización. Líneas más adelante Pavis explica algunas funciones más precisas del término en cuestión:
[Espacialización] La puesta en escena consiste en transponer la escritura dramática del texto (texto escrito y/o indicaciones escénicas) en escritura escénica. 'El arte de la puesta en escena es el arte de proyectar en el espacio lo que el dramaturgo ha podido proyectar solamente en el tiempo' (APPIA, 1954:38). La puesta en escena de la obra de teatro consiste en encontrar para una partitu$r a^{*}$ textual la concreción escénica más apropiada al espectáculo; es 'en una obra de teatro la parte verdadera y específicamente teatral del espectáculo' (Artaud, 1964b: pp.161-162). En suma, es la transformación del texto a través del actor y del espacio escénico (Pavis, 1998: 363)

Esta definición que funciona como piedra basal para pensar en la categoría de Puesta en escena resulta operativa para ponerla en funcionamiento como figura en las narraciones de Bellatin. Las claves para una transposición se encuentran en la idea de una «escritura escénica» por un lado, y una «espacialización» que en Bellatin se da en el plano del texto. ${ }^{7}$

5 Se menciona esta línea de abordaje teniendo en cuenta que en la Universidad de La Plata se nuclea material de archivo que el propio Bellatin facilitó y en que existe un grupo de investigación que está trabajando con algunos de estos aspectos en la obra del escritor. Algunas imágenes del archivo digital se pueden consultar en: https://filologiaun/p.wordpress.com/ archivo-digital-mario-bellatin/

6 Como convención y -para desambiguar la lectura-propongo consignar la noción teatral de puesta en escena en minúscula para diferenciarla de la figura propuesta Puesta en escena que desarrolla a lo largo del artículo.

7 Desde una perspectiva semiótica y diferente Mieke Bal explica el concepto: "Como concepto la mise en escène proporciona una conexión interna entre narrativa, la imagen visual detenida y el psicoanálisis” (2002: 147). 
La escuela del dolor humano de Sechuán: una obra-novela performativa

La escuela del dolor humano de Sechuán es un libro que está conformado por una serie de breves fragmentos, cada uno de ellos cuenta con un título y una suerte de subtítulo que, por lo general, funciona más bien como una didascalia:

Reglas para una posible puesta en escena de la Escuela del dolor humano de Sechuán

Se tendrá que ser muy cuidadoso con la claridad con que se deben expresar las formas de representación por las que este tipo de teatro debe transitar.

En algunas regiones se representa con cierta regularidad lo que algunos estudiosos llaman el teatrillo étnico, bautizado de ese modo porque fue un grupo de antropólogos quienes casi por casualidad detectaron por primera vez esta peculiar forma de actuación. Se trata de cierto tipo de performances, constituidas por una serie de pequeñas piezas, a veces decenas, que en apariencia guardan una supuesta autonomía. Antes de comenzar cada una de ellas, los actores explican al público de una manera breve el contenido o la forma de representación que emplearán para llevarlas a cabo. Sólo a final de estos fragmentos-cada uno lleva un título diferente-se insertan al conjunto dando una sospecha idea de totalidad. Por una extraña razón, cuando este fenómeno ocurre el público entra en un estado catártico bastante particular. Por tal motivo esta forma teatral es una manifestación controlada por las autoridades. Únicamente se permite la representación de un limitado número de piezas al año, solamente para celebrar sucesos importantes para la comunidad (Bellatin, 2005, p. 437).

Este primer fragmento cumple la doble función de explicar a modo de reglas o manual de qué se trata el teatrillo étnico al que la historia referirá y cómo debería representarse teatralmente, al tiempo que se explica cómo está armada la propia ficción. Se trata de escuelas populares con una impronta artística en las que se registran las diversas manifestaciones del dolor a pesar de los intentos de las autoridades por controlarlas, por ejemplo, eliminando a su fundador: Lin Pao. Las historias son diversas pero en todas rige cierto principio: cuerpos expuestos a la violencia a causa de un poder soberano o autoritario. Es decir, padres o madres que disciplinan a sus hijos por medio del dolor obligándolos a utilizar arneses o brazos ortopédicos a partir de la falta de un miembro; un Estado (totalitario) que cercena dedos a aquellos que deciden ejercer su voto; una discípula de la escuela del dolor que ahoga niños en la plaza pública; campesinos que se fotografían empuñando armas y disparándolas al tiempo que esa acción violenta es registrada, etcétera.

A propósito de esta dimensión que ya se percibe como biopolítica, Isabel Quintana (2009) advierte cómo el texto recupera el relato del Estado en donde aparece la cuestión de la regulación de la masa a partir del control que ejerce la propia población y el disciplinamiento. Por ello, en la ficción de Bellatin, el narrador cuenta cómo las prácticas médicas ejercen su poder soberano al infiltrar el cuerpo de un padre agónico y mezquino: "Con un embudo clínico comenzaron a verter un líquido viscoso directamente en la garganta. La botella, puesta boca abajo, se fue vaciando lentamente." (2005: 463). También se narra cómo el control demográfico de la población ejercida por el poder de un Estado totalitario (que es y no es China) a partir de los propios pobladores provoca la muerte del tercer hijo varón de las familias: "Únicamente deseo estar pronto en la fuente, esperando que me entreguen, uno a uno, los terceros hijos varones de las familias. (2005, p. 493)". Me detengo en el equipo de voleibol al que a sus integrantes se les corta los dedos de la mano por haber ejercido su derecho ciudadano:

Los que tuvieran los dedos limpios podían irse, los del dedo manchado, muestra de 
haber cumplido con su deber democrático, debían poner la mano completa sobre la mesa y prepararse para el castigo. Un par de hachazos bastaba para cercenar los dedos de por lo menos tres ciudadanos. Una pila de dedos quedó en medio del poblado (Bellatin, 2005, p. 477).

Este fragmento cuenta acerca de un equipo de voleibol denominado "los democráticos" cuyo nombre adquirieron luego de que se les amputaran los dedos de la mano derecha por su acción. Agamben (2002) retoma y continúa el concepto del "hacer vivir" de Foucault y sostiene que la nuda vida o zoé, es decir, "el hecho de vivir común a todos los seres vivos", no sólo ingresó en la vida política y en el ámbito jurídico sino que- además- el terreno en dónde la decisión sobre la vida es también una decisión sobre la muerte se encuentra constantemente en desplazamiento $y$ entran en una zona de indiferenciación. Es decir, si hay algo que sucede en las democracias modernas es que permanentemente se delinean los criterios y los ejes del hacer vivir y por lo tanto, del dejar morir también. El caso del equipo de voleibol, sin embargo, ingresa en un umbral que va más allá de la nuda vida de Agamben. El filósofo italiano escribe: “...si hay algo que caracterice a la democracia moderna con respecto a la clásica, (...), es que trata constantemente de transformar la nuda vida misma en una forma de vida y encontrar, por así decirlo, el bios de la zoé." (2002, p. 18). Si la democracia moderna politizó la vida en la que constantemente se deben tomar decisiones sobre el umbral de lo que es vida política o vida eliminable, en el nivel de la ficción "los democráticos" brindan un giro particular: bajo el Estado de excepción y cierto impulso de muerte estos cuerpos invitan a la acción:

Es por eso que cuando su prestigio decreció (el de los democráticos) (...) montaron un espectáculo con el que se presentaban en las ferias dominicales de la región. Hacían allí alardes de sus destrezas, mostrando entre otras cosas cómo una mano sin dedos es capaz de duplicar la potencia del golpe en una pelota (Bellatin, 2005, p. 447).

Ante la práctica disciplinaria impuesta en el cuerpo, la respuesta de los democráticos será exhibir su condición. Los cuerpos en la ficción emergen como casos -para usar el término de Schettini $(2005 b)^{8}-0$, agrego , como listas o catálogos. No participan de una historia o un relato sino que estos personajes se nombran, mencionan. Apenas esbozos de historias. Jean-Luc Nancy expresa: "Haría, falta un corpus de una tan infinita simplicidad: nomenclatura desperdigada de los cuerpos, lista de sus entradas, la recitación misma enunciada desde ninguna parte, y ni siquiera enunciada, sino anunciada, registrada y repetida (2003: 43)". Esta ficción de Bellatin dialoga de algún modo con el anhelo del filósofo. Sus breves fragmentos confeccionan una suerte de catálogo, de lista, como un corpus de cuerpos que se exhiben. Nancy en sus conceptualizaciones sobre el cuerpo propone abordarlo sin intentar significarlo. $Y$ el desafío de la escritura es configurar una "excritura" del cuerpo. De manera paradójica, el acto de escribir nos aleja de los cuerpos pero de lo que se trata es de exponerlo para inscribirlo fuera del discurso, Nancy esgrime:

La excripción de nuestro cuerpo, he ahí por donde primeramente hay que pasar. Su inscripción-afuera, su puesta fuera de texto como el movimiento más propio de su texto: el texto mismo abandonado, dejado sobre su límite. No es una «caída», eso ya no tiene ni alto ni bajo, el cuerpo no está caído, sino completamente allímite, en el borde externo, extremo y sin que

“...dos elementos básicos articulan la novela y construyen, en su cruce, las figuras a partir de las que se arma el texto. El primero es el "caso". Sus obras son pequeños laboratorios en los que se exponen uno o varios "rasgos" que constituyen a un personaje como un "ser" de novedad o de rareza, presentado en el texto con fines informativos, iluminadores, sorprendentes o didácticos" (Schuttini, 2005b, p. 14). 
nada haga de cierre (Nancy 2003, p. 14).

El cuerpo en tanto ocupa el extremo es abertura, escribir es el gesto para tocar sentido, por lo tanto, escribir es tocar el cuerpo en el pensamiento de Nancy. $\mathrm{Su}$ abertura da lugar a acontecimientos: gozar, pensar, sufrir. En las ficciones del escritor mexicano, las marcas de estos cuerpos amputados, penetrados, disciplinados poseen el gesto de articular una excritura de los cuerpos. Razón por la cual éstos se registran y repiten ${ }^{9}$ de una a otra ficción, en ese otro corpus que conforma la propia obra del escritor. ${ }^{10}$ Bellatin no sólo establece cierta poética de los cuerpos a partir de su propia falta (me refiero a la carencia de su antebrazo derecho autofigurada en muchas ficciones o analogizada) sino que además lleva al límite de la representación esta preeminencia de los cuerpos. Tal es así que el texto se proyecta en una suerte de tridimensión: por un lado, funciona como guion para que un actor/personaje/performer presente o narre estos fragmentos. Por otro, al tiempo que el actor narra al público, las escenas son representadas por otros actores y por último; el propio texto brinda claves para que el lector persiga una «sospechosa» idea de unidad de la ficción.

Diana Palaversich (2003) en uno de sus estudios preliminares sobre la obra del escritor (parte de este análisis se publica, luego, en el prólogo del primer libro de Obra reunida) refiere al procedimiento o técnica del distanciamiento de Brecht que utiliza el escritor mexicano para explicar el alejamiento del orden de lo conocido al no explicitar lugar y tiempo en la ficciones y como una manera que tiene Bellatin de aproximarse al orden de lo ficticio. Otras formas del distanciamiento que reconoce Palaversich son las indicaciones al lector que aparecen en algunos textos (como $\mathrm{La}$ escuela...) y el uso de nombres de los personajes que designan funciones más que nombres propios tales como «el Amante otoñal», «el Poeta ciego», etcétera. Ahora bien, a partir de lo que sugiere Palaversich la pregunta que surge es qué de la ficción en cuestión (en este caso La escuela...) se conecta con una idea de teatro brechtiana puesto que se trata de un contexto diferente al que producía el dramaturgo.

Lo primero tiene que ver con las indicaciones que se ofrecen en las «didascalias» que encabezan los fragmentos: ya sea el uso de elementos mínimos y el artificio en la utilización de objetos en la posible representación: "se necesitará de una serie de recursos para dar la idea de fuego desatado sin que nadie resulte víctima de una lesión" (Bellatin, 2005, p. 23), o el concepto de narración en el teatro "Se relatará con la mayor economía de recursos posible, cómo se intentó hacer del dolor una experiencia cotidiana" (Bellatin, 2005, p. 11), que es otra característica propia del teatro brechtiano. Por último, existe otro elemento que es la idea de «interrupción» ${ }^{11}$ en el teatro épico que se realiza a partir de las lecturas o reflexiones que los actores hacen en escena, tal como se indican en las «didascalias». En relación con la idea de teatro épico Benjamin esgrime:

...avanza de manera parecida a las imágenes de una cinta cinematográfica, a empello-

$9 \quad$ Y con repetición no me refiero a los personajes (que también suelen reaparecer) sino a los propios cuerpos marcados: carentes de brazos, dedos, piernas o marcados con lunares, o enfermos, etc.

10 Sobre diferentes modos de comprender la escritura y excritura de los cuerpos, ver: la literatura como "discurso cárnico" en Mora Moreno, (2017); la escritura como in-corporación y exorcismo del cuerpo Pinzón Manrique, (2014); la escritura de un cuerpo abyecto en Ávila Rodriguez, (2014) y la escritura desde el cuerpo como un "ver no viendo" en Vargas Quiroz (2014).

11 Cabe señalar que esta idea de "interrupción" también es ejecutada en el teatro de Kantor tal como el propio Bellatin cuenta en una entrevista no ya para hablar de sus textos si no para referirse al conocido congreso de dobles que llevó a cabo en París en el año 2003, en la entrevista que realiza Julia Azaretto (2009), Bellatin explica: "El congreso era como una obra de teatro, la obra que siempre quise hacer. Una pieza de Kantor, en realidad todo fue armado como una obra de teatro que iba a funcionar de acuerdo a las exigencias del público, ésa es una idea muy de Kantor. [...] Kantor era un director polaco que intervenía en las obras y aprovechaba el tiempo real de las obras para transformarlas" [...] 
nes. Su forma fundamental es la del «shock» por el que se encuentran unas con otras situaciones bien diferenciadas de la pieza. Las canciones, los títulos (...) diferencian una situación de otra. Surgen así intervalos que más bien perjudican la ilusión del público (1999, p. 39).

Además, esta idea de intervalo o interrupción en el texto de $L a$ escuela... se desarrolla a partir de la composición general ya que al ser breves fragmentos exige al menos dos acciones en la lectura: por un lado, el gesto de la lectura breve y la interrupción del cambio de página; por otro, el montaje entre fragmento y fragmento ya que las diferentes historias que se esbozan se encuentran diseminadas en los distintos fragmentos desordenados. Esto tiene el propósito de que el espectador/lector pueda tomar distancia crítica con respecto a lo representado/leído. Sin embargo, dos problemas surgen en este recorrido: el más evidente es, tal como señalé anteriormente, que el contexto de producción de Bellatin no está atravesado por la búsqueda de una estética política y proletaria que despierte al público de una falsa conciencia. El segundo, es que Bellatin arbitra otros recursos teatrales (puestos en el texto) con los que el propio Brecht discute: el teatro dramático. Porque es posible encon- trar aquello a lo que el teatro de Brecht trataba de oponerse o diferenciarse -en pos de su realismo y tesis política -que es la búsqueda del efecto catártico del drama aristotélico que ya aparece enunciado en el primer párrafo citado, repaso la frase: "Por una extraña razón, cuando este fenómeno ocurre el público entra en un estado catártico bastante particular (Bellatin, 2005, p. 9)."

Por eso, el texto de Bellatin más que adherirse a una estética (teatral) determinada, dispone del saber escénico (incluyendo los procesos del que formó parte) ${ }^{12}$ para estructurar, escribir y «dar cuerpo» a sus narraciones.

Bellatin en La escuela del dolor humano traza una dimensión performativa que exige cuerpos. O que funda la imagen de un cuerpo: aquel que habla al público pero exige o invita a actores, espectadores y evidentemente a lectores. Por eso, este corpus de fragmentos se hacen cargo de la escritura y sobre el final nuevamente obliga al lector/director a imaginar performativamente más cuerpos:

Los personajes o los medios que se hayan utilizado para la representación deben idear la forma de conocer si los espectadores han logrado hallar vínculos entre los distintos fragmentos. Esta informa- ción es importante para detectar la aparición de algún grado de catarsis. Este texto, tal cual se encuentra redactado, se puede repetir al público (Bellatin, 2005, p. 494).

Una ficción que articula y reclama: el cuerpo del actor que enuncia el texto, el cuerpo de los actores que representan las piezas, el cuerpo del lector que debe cavilar un sentido de totalidad, el del espectador que debe transitar un momento catártico y la lista podría seguir, porque de eso se trata: de un catálogo de cuerpos emergentes vinculados a partir de un corpus de textos.

En relación con esto, Roberto Esposito (2009) realiza un desarrollo sobre la categoría de persona y cuyo punto de partida es detenerse en la cuestión enunciativa. El filósofo italiano propone recorrer ciertas zonas de la filosofía contemporánea para recuperar una perspectiva de lo impersonal desde la concepción de una biopolítica afirmativa. Para ello, recupera un conocido artículo escrito por Emile Benveniste que desarrolla las características principales de la tercera persona pronominal, Esposito explica: "Con la tercera persona ya no está en juego la relación de intercambio entre una $<$ persona subjetiva $>$, el yo, y una $<$ persona no subjetiva $>$, representada

12 No sólo Aristóteles o Brecht sino también otros saberes o tendencias como las de Kantor, aspecto que Conde (2013) analiza para la obra de Poeta ciego tal como se explicita en el apartado que sigue. 
por el tú, sino la posibilidad de una persona no personal o, más radicalmente, una no-persona." (154). Justamente por su carácter, esta tercera persona remite a un referente externo que se encuentra ausente de la situación de enunciación y si bien puede ser algo o alguien, al no ser específico cobra la fuerza de ser extensible a todos. Por eso, la tercera persona aparece a través de figuras como "la justicia", "lo neutro" de Blanchot o la propia categoría de "vida" pensada por Foucault y Deleuze respectivamente. Para el filósofo, la convergencia de una vida foucaultiana que lucha y se resiste; y la de un devenir animal deleuziano contribuyen a la configuración de un pensamiento de lo impersonal. De este modo, la persona viviente, coincidente con la vida misma, remite a la figura de la tercera persona: la no-persona inscripta en la persona (o la persona abierta a aquello que aún nunca ha sido).

Desde la óptica de Espósito (2009) La escuela del dolor humano de Sechuán reclama a un tercer cuerpo ausente. Es decir, la ficción pone en juego dos movimientos: por un lado, la composición de los fragmentos que integran la ficción, precedidos por una suerte de didascalia, ejerce un efecto de pivote hacia el segundo movimiento: la aparición de un tercer cuerpo ausente que se encuentra afuera del enunciado.

Poeta ciego: cuerpo performático, texto performativo

Tal como anticipamos al comienzo de esta sección, la novela Poeta ciego (2010) arrastra un proceso performativo en dos sentidos: en primer lugar, porque este texto o pre-texto como especifica Conde (2013) se construye a partir de recortes de ficciones o texto previos tales como Efecto invernadero y en segundo lugar, porque a la vez, la versión publicada de Poeta ciego fue corregida cuando se trabajó con la adaptación teatral Black -Out (los cadáveres valen menos que el estiércol). ${ }^{13}$

Las ficciones de Mario Bellatin son escrituras en las que existe una clara preeminencia de los cuerpos al mismo tiempo que el propio cuerpo de la escritura se inscribe en una práctica performática ( $\mathrm{y}$ en algunos casos performativa) ${ }^{14}$ : cuerpos marcados, cuerpos carentes, cuerpos cercenados, cuerpos inmóviles, cuerpos que bailan; inscriptos en rituales, ceremonias que posibilitan cierto continuo narrativo al mismo tiempo que esa escritura se fija a partir de juegos con la repetición y variación del material narrativo como también de cierta tematización de los procedimientos que muestra, (señala a modo de un deíctico) el acto de escritura incluyendo al lector como parte de ese proceso.

El propósito es analizar cómo esta dimensión, que se supone performativa desde el proceso de composición de la novela, ostenta su otra cara en la escritura: una figuración performática de los cuerpos. Para desarrollar esta propuesta se tendrán en cuenta dos aspectos de la novela: la presencia de prácticas rituales como las ceremonias de iniciación, danzas y juegos teatrales, por un lado; y la disposición de la escritura en torno a estas prácticas, por otro.

13 Para conocer precisiones acerca del proceso de escritura de Poeta ciego desde el punto de vista genético, ver Conde (2013).

14 Corresponde aquí hacer una aclaración. Este artículo utiliza dos términos: performativo/performático/a que conviene distinguirlos. El adjetivo del término performance no es performativo sino performático/a. Pues, el primero refiere a los actos de habla performativos desarrollados por el filósofo del lenguaje J.L. Austin. Esta distinción no entra en conflicto pero sí alude a dos cuestiones diferentes que pueden ser complementarias. En el primer caso, un hecho cultural, una intervención, un libro pueden ser "performáticos" por su carácter artístico, cultural o de espectáculo; en cambio, en el segundo caso, el término opera en el nivel del lenguaje, un "performativo feliz" como lo llama Austin constituye un acto legal. Para más detalles ver Taylor, D. y Fuentes, M. (comps) (2011). Estudios Avanzados sobre performance. México: FCE. A su vez Brijaldo, G (2014) en su artículo "Interpretaciones íntimas sobre la escritura performativa", caracteriza la escritura performativa como una "postura epistemológica, porque abre el campo de posibilidades teóricas y creativas, y afirma un espacio para poner en juego saberes interdisciplinares", así como una "práctica de cuerpo" (113-114). 


\section{Los rituales y el teatro}

La historia de Poeta ciego comienza con el origen desconocido de este personaje. El narrador cuenta que el poeta fue recogido por una familia de pescadores y que desde niño ya mostraba sabiduría al punto tal que las personas del puerto se acercaban para escucharlo. En ocasiones él palpaba extensos lunares de toda la familia de pescadores. A los nueve años dicta su primer poema. Luego, emprende un peregrinaje por la costa del país. Al llegar a la ciudad capital, su nombre aparece en todos los diarios de la ciudad. Ocupa el primer lugar en el ingreso a la universidad más importarte del país. A partir de esta noticia, una pareja adinerada lo adopta creyendo reconocer en el poeta al hijo secuestrado años atrás. De este modo, el poeta se instala en la ciudad y funda una Organización en las que se conforman enseñanzas, reglas y prácticas impartidas por el poeta y más adelante, por su ayudante-esposa Virginia y el pedagogo Boris. En este contexto el narrador en tercera persona contará en detalle de qué se tratan estas prácticas que los discípulos y/o aspirantes realizan como también comportamientos transgresores a las reglas de la Organización de los que resultarán muertes y encarcelamientos.

Independientemente de la teatralización de la obra, en el pla- no de la escritura la novela figura prácticas rituales y teatrales:

Los aspirantes, eran arrodillados en un suelo cubierto con pequeñas piedras filosas. En los dos extremos del campo, había unas empalizadas, formadas por cruces y espadas clavadas en el suelo. En esta etapa del acto, la Doctora Virginia se encontraba trepada, en un atrio de madera, construido especialmente para esas ocasiones. Durante las tres horas siguientes, los aspirantes debían repetir, en voz alta, los principios fundamentales de la Organización. Todos los aspirantes tenían, en las manos, una vara de madera negra, que les servía, para apartar las fuerzas del mal. Desde donde se encontraba ubicada, la Doctora Virginia decía, en voz alta, la primera parte de las oraciones, para que luego los aspirantes las completaran en forma correcta. Era imprescindible que se guardara la más absoluta compostura (pp. 17-18).

Esta ceremonia de iniciación sucede conforme a las propias reglas de las que estas prácticas se nutren, por ejemplo, a partir de principios como el ritmo o la repetición. De modo semejante, la Organización que preside el poeta, incluso después de su asesinato, exige el despliegue de juegos teatrales:

Recomenzaron las voces de los parlantes, para guiar un rápido ejercicio teatral, por el cual cada asistente debía cerrar los ojos, y reconocer, a los compañeros desnudos, por medio del tacto. A cada momento, las voces hacían referencia al Celibato Obligatorio. En medio de la espesa nube de vapor, era apenas perceptible el espectáculo, de estos hombres y mujeres buscando tocarse (Bellatin, 2010, pp. 27-28).

Y de modo aparentemente diferente, también ocurre una suerte de "espectáculo" entre ritual y erótico en lo que se conoce como Palacio de las Mujeres Desnudas:

La estructura formaba pequeñas casetas, con vistas a un reducido espacio circular. Cada una de las casetas, tenía dos filas de sillas y un vidrio, a través del cual se veía el minúsculo escenario. Antes que el Pedagogo Boris entrara, el encargado le preguntó cuánto tiempo pensaba mirar mujeres. El Pedagogo Boris no contestó, pero le extendió algunos billetes. Era el único cliente. Apenas traspasó el umbral, una música bailable comenzó a sonar. Entró en la primera cabina. A ambos lados, había letreros, escritos con material fosforescente. Tomó asiento en una silla. Al instante, se levantó una cortina, y salió al escenario. El Pedagogo Boris y la mujer estaban separados por un vidrio. La mujer trataba de bailar al son de la música, pero no tenía mucho espacio para hacerlo. Estaba completamente desnuda, y tenía la 
cara cubierta con una máscara. Un extenso lunar aparecía sobre uno de sus hombros (...) De pronto alguien entró en la cabina y se sentó a su lado [del Pedagogo Boris]. Estaba todo tan oscuro, que no se podían adivinar las características de esa persona. El Pedagogo Boris comenzó a ser acariciado en forma disimulada. Al mismo tiempo, le decían al oído, que le iban a explicar aquello que estaba viendo a través del vidrio. La voz continuó hablando. Expuso las ventajas de no cometer actos carnales (Bellatin, 2010, p. 22).

Extraigo estas tres escenas (hay algunas otras) para ponerlas en correlación, aunque se trata de tipos acciones y personajes diferentes, en todas rige una serie de principio o reglas: cuerpos que se someten a un "acto", que realizan determinadas acciones siguiendo normas propias del grupo al que pertenecen (La Organización del poeta o la Nueva Organización).

Al mismo tiempo, estas acciones no pueden ser escindidas de otros sucesos que la novela expone: el asesinato del poeta en manos de la Doctora Virginia quien lo encontró "rompiendo" el principio del Celibato Obli- gatorio cuando lo descubre teniendo sexo con la enfermera; la persecución y encierro a Ana, la extranjera, para extirparle el lunar del hombro, el deseo reprimido que los discípulos de la Organización deben tolerar para preservar los principios de la Organización, entre otros hechos.

Cabe explicitar que Poeta ciego carga al menos dos lecturas alegóricas: la primera refiere a que la novela gira en torno a sociedades totalitarias ${ }^{15}$ tales como, la Unión Soviética; Y la segunda, que la novela trata acerca del horror impulsado por Sendero Luminoso durante los años que Bellatin vivió en Perú y en donde realizó el primer manuscrito de la novela. Ésta última lectura fue refrendada por el propio escritor en más de una ocasión en diversas entrevistas. ${ }^{16}$ Más allá del referente (Sendero Luminoso o la Unión Soviética) se busca narrar la violencia a partir de estas prácticas descriptas que los personajes ejecutan y que se pueden aglutinar bajo el concepto de "performáticas". En todos ellos, circunda la violencia y la sexualidad.

El teórico teatral Richard Schechner (2000) se detiene en esta relación (vía Girard) para ex- plicar que el ritual sublima a la violencia y luego explica: "Todo esto suena muy parecido al teatro-especialmente un teatro cuya función es catártica, o al menos un teatro que «re-dirige» energías violentas y eróticas. Catártico o no, el teatro siempre manufactura sustitutos, se especializa en multiplicar alternativas" (199). Más allá de esta línea sugerente para pensar formas de violencia no sólo en relación a lo erótico sino también para desarrollar este sentido alegórico que se mencionó en Poeta ciego, me parece importante puntualizar, a los propósitos de este apartado, en algunas cuestiones relativas al ritual para reflexionar su presencia en el texto literario.

Schechner compara los rituales culturales (del tipo shamánico) con los teatrales y señala que la diferencia se da en que, en el teatro, el personaje es un sustituto de un sustituto. ${ }^{17} \mathrm{Y}$ es en este sentido, que en Poeta ciego existen dos niveles de figuración y representación: por un lado, se figura una ceremonia, un baile o un ejercicio teatral y por otro, sucede una «representación» en el nivel de la trama: Ana, la extranjera representa un baile para el Pedagogo Boris, los discípulos de la Organización representan el tacto de los cuerpos a través de los

\footnotetext{
Esta lectura aparece mencionada en el prólogo de Obras reunidas por Diana Palaversich (2005).

16 "Lo que encuentras en ese libro es cierto y es porque en realidad es Sendero Luminoso. Los años que yo viví cercano a Sendero Luminoso, a los horrores cotidianos, donde el horror ya genera más horror y horror, y siempre hay un lugar para el horror mayor, no hay límites. Entonces, de alguna manera era como una respuesta a eso, interna. Pero, obviamente no podía yo, no me interesa, hablar de política ni mucho menos, pero sí ver qué mecanismos pueden generarse para que se establezca un espacio tan terrible de violencia.[...]". Cf. Goldchluk, G. (2000) Entrevista a Mario Bellatin. Recuperado el 12 de noviembre de 2017 en http://www.foxitsoftware.com For evaluation only.

17 En el sentido que el actor sustituye a un personaje que a su vez no es una persona "real."
} 
ejercicios teatrales; o bien, Virginia representa los principios de la Organización frente a su público, quienes a su vez, representan a la sociedad que forman como secta u organización.

Los rituales y ceremonias funcionan como principios regulatorios de un sistema o conjunto de sistemas. Y tanto en la cultura oriental como occidental (aunque de modo diferente) el ritual, las ceremonias y los ritos de pasaje establecen vínculos con lo teatral y con el entretenimiento. Schechner (2000) a partir de determinados estudios acerca de los rituales, ceremonias, danzas (entre otras manifestaciones sociales) perteneciente a diversas comunidades $^{18}$ reflexiona cómo el teatro nace del ritual pero también el ritual nace del teatro y no como algunos antropólogos sostienen, que sólo del ritual se origina el teatro ${ }^{19}$. En esta línea, Schechner distingue entre eficacia y entretenimiento. Mientras que la primera busca resultados; el entretenimiento busca diversión. Sin embargo, ninguna de estas características está asociada exclusivamente al ritual o al teatro respectivamente, sino que dependiendo del caso, ambas están contaminadas de los dos atributos aunque suele haber uno que predomine:

Todo el continuum binario de eficacia/ritual-entretenimiento/teatro es lo que yo llamo "performance". La performance se origina en el impulso de hacer que pasen cosas y de entretener; obtener resultados y juguetear, detectar significados y pasar el tiempo; ser transformado en otro y celebrar ser uno mismo; desaparecer y exhibirse...(p. 59).

Esta retroalimentación que Schechner estudia opera en el nivel del texto figurando cuerpos performáticos. En el sentido en que no es posible separar las acciones de estos personajes (entre sus figuraciones y las representaciones que éstos realizan) y por lo tanto, los lectores intervienen como colaboradores en la búsqueda incesante de sentido. En el nivel de la escritura esto solo es posible a partir de su disposición narrativa.

\section{El ritual de la escritura}

La novela está narrada en tercera persona y estas prácticas se narran desde el recurso del "distanciamiento" 20 . Esto se logra a partir de la repetición de pequeños sintagmas que vuelven a pronunciarse, a veces con ligeras variaciones como si no hubieran sido escritos con anterioridad "y extendió toda la mano sobre el lunar, que la Extranjera Anna, el día anterior, había olvidado acicalar."(29), “... tocar el lunar que en esa oportunidad la Extranjera Anna había acicalado con el cuidado habitual (53)". A veces, estas repeticiones emulan las fórmulas provenientes de la oralidad, a la manera de reglas mnemotécnicas. De este modo, la escritura se vuelve regular como aquello que cuenta.

Alan Pauls (2005) para argumentar acerca del carácter "artístico" de Bellatin por encima del de "escritor" analiza:

Así empieza por ejemplo $L a$ escuela del dolor humano de Sechuán: «En algunas regiones se representa con cierta regularidad lo que algunos estudiosos llaman el teatrillo étnico». Lo que importa aquí, por supuesto, es la palabra «regularidad»: [...] eso que describe tiene reglas,

18 Por ejemplo, indaga la celebración de la comunidad tsembagas en las Tierras Altas de Papúa Nueva Guinea.

19 Schechner (2000) esgrime: "Las teorías ortodoxas postulan que el ritual precede al teatro, del mismo modo que la eficacia y el monismo ("unicidad primitiva) preceden al entretenimiento. Un lugar común en las interpretaciones del arte de las cuevas del Paleolítico es decir que alguna clase de "ritual" generó el arte-y por ritual se quiere decir alguna clase de performance seria, eficaz, orientada a obtener resultados, sea para asegurar la fertilidad, aplacar los poderes que controlan la cacería, mantener el equilibrio entre machos y hembras, hacer iniciación o alguna otra cosa. Todas esas cosas o alguna de ellas, pueden ser verdad, pero no son toda la verdad. El entretenimiento, el pasar tiempo jugando y divirtiéndose (no hablo de la pasividad y el aislamiento del "arte por el arte" sino de una participación activa en el proceso de hacer arte) se entretejen y son inseparables de todos los aspectos eficaces del arte más temprano (pp. 56-57)".

20 Ya no en el sentido estrictamente brechtiano (aunque de él derive este procedimiento) si no en un sentido general de las posibilidades que la técnica -ya reapropiada por escritores y dramaturgos- ofrece. 
patrones, modalidades más o menos fijas de aparición, y por lo tanto siempre está llamado a suceder una vez más, a repetirse. [...] En realidad, más que de la narración, el presente es el tiempo de la transmisión, en el sentido en que se hablaba, al menos hasta hace algún tiempo, de "transmitir" un espectáculo deportivo, un partido, una carrera, una competencia. [...] Pero transmitir, en cualquier caso, es poner al relato en una condición paradójica, a la vez de potencia y de desamparo: en una transmisión el relato es todo, pero es un todo que gotea, que pierde, que se pierde - por exhaustivo que sea- siguiendo las huellas de la experiencia que trasmite. En esa especie de manía del presente que afecta a Bellatin veo también el síntoma de su impostura, la fragilidad de su identidad de escritor o el peligro que corre. Nunca la ficción ha sido menos autónoma que aquí, nunca menos "cerrada" y soberana, y nunca ha puesto tanto en evidencia hasta qué punto necesita de otra cosa para existir, y hasta qué punto esa otra cosa ya está alojada en su corazón, desgarrándola, y la empuja a salirse de sí (Pauls, 2005).

Recupero este extenso fragmento porque Pauls ejemplifica con el texto de La escuela del dolor humano de Sechuán un rasgo característico de los textos de Bellatin. Si bien, en efecto, se evidencia esta idea de transmisión, del efecto que genera en el lector de que eso que se cuenta "está sucediendo", Pauls "pasa de largo", lee una suerte de vacío en esa idea de los rituales que sólo "suceden" para explicar que Bellatin necesita algo más que la literatura (necesita el happening, la fotografía, la performance) y debe "buscar afuera de la literatura" y en ese sentido el traje de escritor le queda corto. Además el concepto de "transmisión" que piensa Pauls no es el de la pedagogía, de la enseñanza sino otro: el de la "emisión televisiva". Idea cercana a la que utiliza Laddaga (2007) para referirse al carácter emisivo de ciertas literaturas (incluye a Aira, Bellatin, Noll), y emparentado con las tecnologías (websites, juegos interactivos) que permiten otras formas de "navegación". En este sentido el título "teatro y escuelas" que Laddaga elije para leer a Bellatin es sugerente para pensar estas relaciones entre las representaciones del discurso pedagógico y el teatro, sin embargo, su argumentación se desvía hacia las formas digitales, contemporáneas, de modos de circulación de discursos, de producción y formas de leer:

Tanto como emergen, en los universos en los que Bellatin o Aira escriben (y en los que saben que sus libros circulan), otras formas de circulación de discursos (y otros imaginarios de la circulación asociados a ellos). Pienso sobre todo en aquellas formas que se despliegan en el uni- verso digital-websites personales o espacios de discusión en la red, juegos interactivos de video-, pero también en las nuevas formas de la televisión... (p. 143).

Laddaga se preocupa por "contemporizar" la escritura de Bellatin, hacerla inteligible al mundo globalizado. Cuando en realidad, aquellos rituales, ceremonias, prácticas teatrales que resultan extemporáneos revisten esa cuota inactual, arcaica con la que Agamben caracteriza "lo" contemporáneo: "La contemporaneidad se inscribe, en efecto, en el presente, signándolo sobre todo como arcaico, y sólo quien percibe en lo más moderno y reciente los indicios y las signaturas de lo arcaico puede ser su contemporáneo" (p. 79).

Volviendo al tema de esta escritura regular que Bellatin produce en Poeta ciego, ciertas escenas como la de la ceremonia de iniciación son narradas en su totalidad más de una vez. Estas repeticiones envuelven la progresión narrativa, la ralentiza y produce el efecto de estar leyendo lo mismo una y otra vez. Una escritura que avanza a partir de la circularidad. Una escritura que se vuelve un pequeño ritual:

Cada fragmento me parece que es la representación de mi ritual de escritura. Para ejercitar la escritura pretendo buscar tiempos y espacios 
cerrados en sí mismos. Cada fragmento es lo que dura una de esas sesiones. Después de tener muchos retazos, que de cierta forma siento que están comunicados entre sí, hago una labor de convertirlos en una suerte de propuesta, de hacerlos transmisibles al otro. Finalmente queda a la vista una mínima parte de estos ejercicios. ${ }^{21}$

La escritura de Poeta ciego alimenta el mito biográfico del escritor, sus ejercicios escriturarios, su propia práctica se ritualiza al ponerla en contigüidad en el corpus de ficciones que, como se ha señalado, algunos de estos fragmentos aparecen en textos como Efecto invernadero (2005) (anterior a Poeta ciego) o en Lecciones para una liebre muerta (2005). Y como se mencionó al final del apartado, nuevamente el lector es quien establece estas operaciones de contigüidad entre las partes. De esta manera, se produce el desplazamiento del teatro al ritual:

El desplazamiento del ritual al teatro ocurre cuando un público participante se fragmenta en un grupo que asiste porque se anuncia el espectáculo, que paga la entrada, que evalúa lo que va a ver antes de verlo, mientras lo ve y después. La movida del teatro al ritual ocurre cuando el público, de ser un grupo de individuos separados se transforma en un grupo o congregación de participantes (Schechner, p. 59, énfasis mío).

Bellatin permite escribir un texto performativo a partir de estos procedimientos y estrategias: repetición y variación de breves sintagmas en la ficción, repetición con variantes de una a otra ficción del propio Bellatin, preeminencia del tiempo presente, un tono despojado, etcétera, mientras, al interior de su ficción, diseña una Puesta en escena de rituales, ceremonias y actuaciones que corporizan a los cuerpos. ${ }^{22}$ Le Breton (2002) desarrolla cómo en las representaciones modernas y occidentales de los cuerpos, éstos realizan ritos de borramiento:

En la vida de todos los días estamos guiados por una red de ritos que borran la evidencia del cuerpo al mismo tiempo que, con tranquilidad, lo inscriben en la situación vivida [...] Las interacciones se siguen produciendo protegidas por el borramiento ritualizado de las manifestaciones corpo- rales. Un examen más atento muestra que, más allá de las apariencias, a pesar de, quizá, sutiles modificaciones y una menor rigidez, no conviene exponer el cuerpo más allá del marco de los ritos que puntualizan el desarrollo de la vida social y que lo mantienen en el claroscuro de la presencia-ausencia (127-128 énfasis mío).

Sin embargo, los rituales en Poeta ciego son justamente lo contario a las conductas conforme a leyes o reglas de la vida social. Estas ceremonias, juegos teatrales y rituales permiten transformar la negatividad de los cuerpos que quieren borrarse en afirmación y "dan cuerpo" o corporizan a los cuerpos figurados de la ficción, brindándoles visibilidad.

\section{Los cuerpos en escena}

La escuela del dolor humano de Sechuán y Poeta ciego son dos textos de Bellatin que proponen una relación con lo escénico. Esta propuesta no sólo sucede en momentos previos o posteriores a la realización de una obra teatral, por ejemplo. Sino que se trasponen en el nivel de la trama ofreciendo una Pues-

21 Entrevista a Mario Bellatin 03 de agosto de 2007. Recuperado el 5 de octubre de 2017 en http://asesinostimidos. blogspot.com.ar/2008/08/entrevista-mario-bellatn.html

22 Schechner (2000) explica. "Las acciones del ritual y del humano están muy cerca del teatro. En el teatro, también, la conducta se desarregla, se condensa, se exagera y se hace rítmica. El teatro usa vestuario colorido, máscaras, pintura de cara y cuerpo que impresionan tanto como la cola de un pavo real o los cuernos de un anta. En el teatro se representan viajes peligrosos y conflictos mortales. Hasta las farsas y comedias apenas si esconden sus subtextos violentos. La violencia ritual, como la del teatro, está simultáneamente presente y ausente, mostrada y diferida. Las conductas rituales se exhiben mientras los "sucesos reales" se difieren" (196). 
ta en escena literaria que hace visibles cuerpos en acción, performáticos, ausentes y excritos (en el sentido de Nancy 2003) para conjurar un discurso en el que cuerpo se afirme en su extensión intentando no cerrar sentidos que lo expliquen.

En estas ficciones de Bellatin se despliegan corporalidades, subjetividades, actuaciones que escapan a una lógica homogénea de producción de cuerpos o subjetividades que la globalización impone. Por ello, se privilegian personajes anómalos, marginales que adquieren características determinadas tales como constituirse en cuerpos impersonales siguiendo a Esposito en tanto y en cuanto muchas veces se inscriben fuera de la enunciación, es decir, como tercera persona en la que la no-persona se inscribe en la persona abierta a lo que aún no ha sido. Una tercera persona que en La escuela del dolor humano de Sechuán se configura a partir de un texto que sitúa cuerpos fuera de la trama exigiendo el cuerpo de los actores y lectores para darle espesor a la ficción. También es posible reconocer cuerpos excritos en términos de Nancy, esto sería cuerpos que intentan salirse de la escritura para excribirse fuera de ella, empresa que resulta prácticamente una imposibilidad pero que, en ciertos momentos, las ficciones permiten abrir esta vía y mostrar cuerpos excritos. Estas nociones filosóficas que atraviesan el análisis de los textos me han permitido articular desde la figura de la puesta en escena modos en que estas cuestiones sobre actuaciones, cuerpos y subjetividades se manifiestan, se diseñan mostrando un pensamiento que se presenta como complejo a la hora de tratar estos asuntos. Si estos textos obligan a pensar críticamente estos vaivenes entre la literatura y el arte motivándonos a salir del terreno estrictamente literario; también creo que es posible pensar el movimiento contrario, en la forma en que la propia literatura busca estrategias para traccionar ese escenario actual y "vivo" del arte contemporáneo a la instancia de mediación de la escritura. Como si se tratara de un volver a la literatura, sus formas, estrategias, procedimientos, búsquedas para figurar, representar, dislocar "el afuera" dialogando con sus propias tradiciones (literarias) estéticas, poéticas, históricas al mismo tiempo que centran la atención en las prácticas contemporáneas del arte e incluso interviniendo desde las acciones de los escritores. La literatura que siempre busca más acá y más allá de su medio, se dialectiza, dinamiza buscando flujos de comunicación oblicuos, anacrónicos y siempre reflexivos con el mundo. La figura de la puesta en escena propuesta ha permitido esa entrada y salida de la literatura para señalar que ésta siempre está dispuesta a habitar todos los mundos: ficcionales y no ficcionales. La literatura como campo expandido no solo ocurre en un movimiento "hacia afuera" sino también en su propio interior. 


\section{Bibliografía}

Agamben, G. (2002). Homo Sacer I. España: Editora Nacional Madrid.

Agamben, G. (2003) “¿Qué es lo contemporáneo?”. Otra Parte, 20, 77-80.

Ávila Rodríguez, A. (Enero - Junio de 2014). De la germinación de lo siniestro: La Belleza en Espejo Roto. La Palabra (24), 99 - 10.

Azareto, J. (2009). Entrevista a Mario Bellatin. Recuperado el 30 de junio de 2017 en http://cle.ens-lyon. fr/espagnol/entrevista-a-mario-bellatin-68252.kjsp

Bal, M. (2002). Conceptos viajeros en las humanidades, una guía de viaje. Murcia: Cendeac.

Bellatin, M. (2005[2001]). La escuela del dolor humano de Sechuán. En Obra reunida. Buenos Aires: Alfaguara.

Bellatin, M. (2010[1998]). Poeta Ciego. Buenos Aires: Mansalva.

Brijaldo, G. (Enero - Junio de 2014). Interpretaciones Íntimas sobre la Escritura Performativa. La Palabra (24), $111-117$.

Conde, L. (2013). Mario Bellatin: Una escritura tridimensional. VI Jornadas de Filología y Lingüística, 7 al 9 de agosto de 2013, La Plata, Argentina. En: Memoria Académica. Recuperado el 20 de diciembre de 2017 en http://www.memoria.fahce.unlp.edu.ar/trab_eventos/ev.3847/ev.3847.pdf

Esposito, R. (2009). Tercera persona, política de la vida y filosofía de lo impersonal. Buenos Aires: Amorrortu.

Esposito, R. (2011). El dispositivo de la persona. Buenos Aires: Amorrortu.

Esposito, R. (2016). Las personas y las cosas. Buenos Aires: Eudeba.

Garduño, O. (2013). Entrevista a Mario Bellatin. Revista Replicante. Recuperado el 15 de diciembre de $2017 \mathrm{de} \mathrm{http://revistareplicante.com/entrevista-con-mario-bellatin/}$

Goldchluk, G. (2000) Entrevista a Mario Bellatin. Recuperado el 12 de noviembre de 2017 en http:// www.foxitsoftware.com For evaluation only.

Hartog, F. (2007). Regímenes de historicidad. Presentismo y experiencias del tiempo. México: Universidad Iberoamericana.

Kozak, C. (ed.) (2015). Tecnopoéticas argentinas, archivo blando de arte y tecnología. Buenos Aires: Caja negra editora.

Laddaga, R. (2007). “Teatros y escuelas”. En Espectáculos de realidad, ensayos sobre la narrativa latinoamericana de las últimas dos décadas. Rosario: Beatriz Viterbo. 
Larrain, R. (2006). Entrevista a Mario Bellatin. Revista Orbis Tertius, 11(12).

Los asesinos tímidos, entrevista a Mario Bellatin. (s.f.) recuperado el 8 de marzo de 2015 en http:// asesinostimidos.blogspot.com.ar/2008/08/entrevista-mario-bellatn.html

Mora Moreno, S. A. (enero-junio de 2017). Carne y nada más: la configuración del discurso cárnico en La Carne de René de Virgilio Piñera. La Palabra, (30), 243 - 259.

Nancy, J.L. (2003). Corpus, Arena Libros, Madrid.

Palaversich, D. (2003). "Para una lectura de Mario Bellatin”. Revista Chasqui. 32, (1), 25-38.

Palaversich, D. (2005), “Prólogo”. Bellatin, Mario, Obra Reunida. Alfaguara. Buenos Aires.

Pauls, A. (2005), "El problema Bellatin", en El interpretador, 20, www.elinterpretador.net, [última consulta 5 de agosto de 2011]. Actualmente disponible en http://salonkritik.net/10-11/2011/06/ el_problema_bellatin_alan_paul_1.php

Pavis, P. (1998). Diccionario de teatro. Barcelona: Paidós.

Quintana, I. (2009), "Escenografía del horror: cuerpo, violencia y política en la obra de Mario Bellatin”. Revista Iberoamericana, vol. LXXV, 227.

Pinzón Manrique, H. (Enero - Junio de 2014). La Literatura como InCorporación: El Cuerpo como Proceso. La Palabra (24), 91 - 97.

Schechner, R. (2000). Performance. Teoría y prácticas interculturales. Buenos Aires: Libros del Rojas.

Schettini, A. (2005a), "La escuela del dolor humano de Sechuán” Revista El interpretador, 20, www. elinterpretador.net, [última consulta 5 de junio de 2005]

Schettini, A. (2005a). La escuela del dolor humano de Sechuán. RevistaEl interpretador, 20. Recuperado el 5 de junio de 2005 en www.elinterpretador.net

Schettini, A. (2005b). En el castillo de Barbazul. El caso Bellatin. Otra parte, 6, Buenos Aires, pp. 1417.

Taylor, D. y Fuentes, M. (2011) (Comps.).Estudios avanzados de Performance. México: Fondo de Cultura Económica.

Vargas Quiroz, A. P. (julio - diciembre de 2014). Me gustan tus ojos miopes (o del diálogo con Hélène Cixous para llevar al cuerpo, a la literatura, a la vida). La Palabra (25), 143-156. 